\title{
Erratum
}

\section{Effect of light on vanillin precursors formation by in vitro cultures of Vanilla planifolia}

\section{Daphna Havkin-Frenkel ${ }^{1}$, Andrzej Podstolski ${ }^{2}$ \& Dietrich Knorr ${ }^{3}$}

${ }^{1}$ David Michael and Company, Inc. 10801 Decatur Road Philadelphia, PA 19154 USA; ${ }^{2}$ University of Warsaw, Institute of Botany, Krakowskie Przedmiescie, 26/28 00-927/1, Warsaw, Poland; ${ }^{3}$ Department of Food Technology, Berlin University of Technology, Königin-Luise-Strasse 22, D-14195 Berlin, Germany

Received 1 November 1994; accepted in revised form 6 February 1996

Plant Cell, Tissue and Organ Culture Volume 45, No. 2, pp. 133-136 (May 1996)

Figure 1 which was omitted from the above article is printed below. Our apologies for any inconvenience caused by this omission.

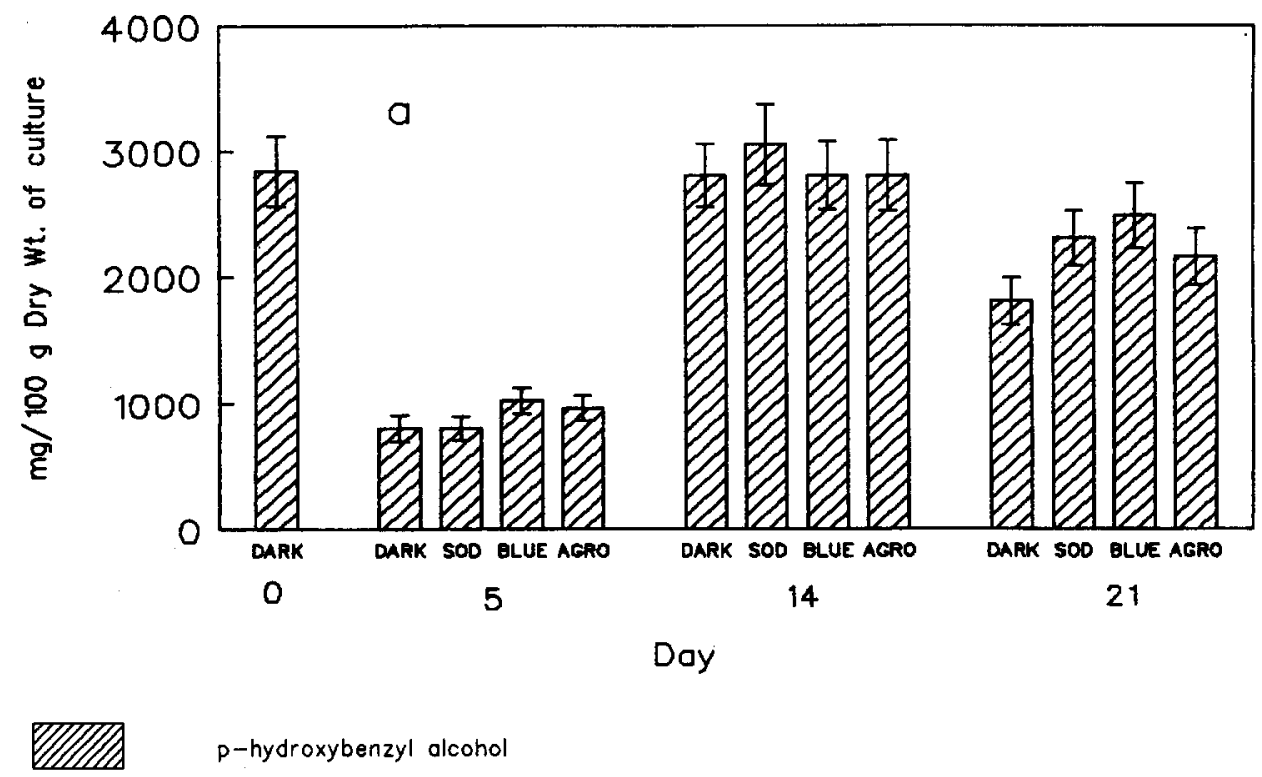

Figure I. Effect of light quality on the accumulation of vanillin and possible precursors by V. planifolia cultures. 

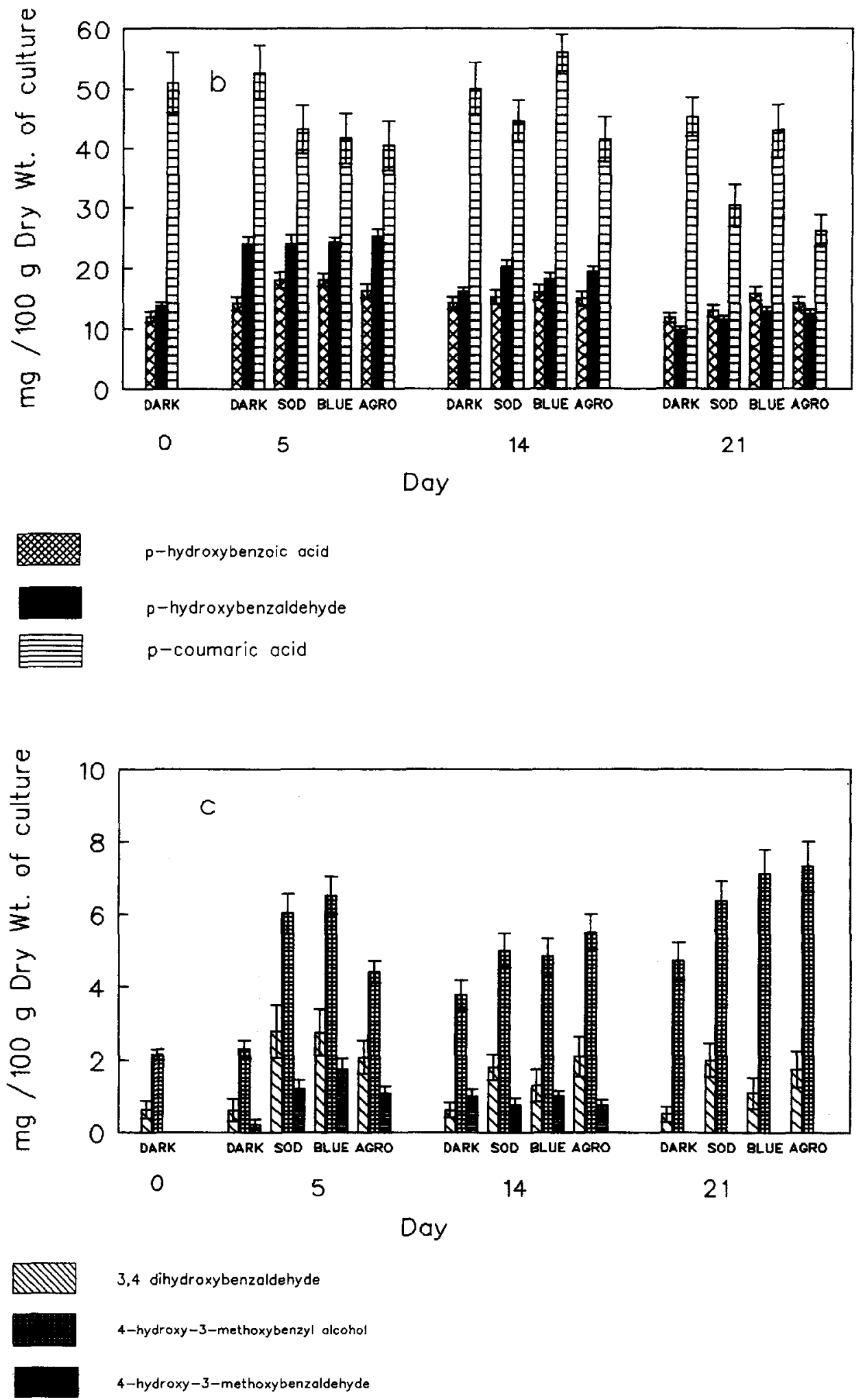